\title{
A LINGUAGEM CINEMATOGRÁFICA COMO DISPOSITIVO PEDAGÓGICO NA EXPERIÊNCIA DE SI*
}

\author{
Viviane Rodrigues Alves de Moraes
}

\begin{abstract}
O que o cinema deve apreender não é a identidade de uma personagem real ou fictícia, através de seus aspectos objetivos e subjetivos. É o devir de personagem real quando ela própria se põe a 'ficcionar', quando entra em flagrante delito de criar lendas', e assim contribui para a criação de seu povo. (DELEUZE, 2007, p.183)
\end{abstract}

Formar professores e professoras capazes de atuar de forma consciente, crítica e criativa, alinhando suas histórias de vida à percepção da complexidade do sistema educacional constitui-se uma meta presente no ideário de muitos formadores e pesquisadores (ALARCÃO, 1996). Mas, de que formação estamos falando? Da formação do professor(a) "ideal" para atuar em sistema colocado a priori como o "verdadeiro", o "correto", a "origem" e o "bem", dentro de uma visão platônica, e que garantiria, efetivamente, as condições ideais para a obtenção de um padrão pré-determinado de profissional por currículos e programas? Uma fôrma, forma-professor(a) que favoreça certas noções de "competências", "habilidades necessárias", "perfis desejáveis ao profissional"? Pensar uma formação que segue esses moldes poderia propiciar um sentimento de algo a se perseguir que nunca encontramos, pois como no mundo das ideias de Platão, caberia somente copiar a perfeição, se submeter a modelos, identificar-se com características, assemelhando-se às formas, e, àqueles que são do mundo das aparências, restaria, apenas, o sentimento da falta. Dessa maneira, nos cabe o compromisso de problematizar qual tipo de formação estamos construindo com nossos alunos e alunas.

Esse compromisso intrínseco de formação é permeado por dificuldades, pois não podemos esquecer que estamos inseridos em um sistema educacional que tem uma história cuja construção se dá para além de seus limites, e é constituído por dimensões relacionadas à cultura, à filosofia, à sociologia, à psicologia e à antropologia, inserido em uma

"DOI - 10.29388/978-65-86678-66-6-f.193-210 
macropolítica, e atravessado, a todo momento, por micropolíticas, no plano da imanência, das relações concretas, onde passado e presente se atualizam, produzindo a diferença (CARVALHO, 2013, p.02). Nesse contexto, Villani (2008) coloca que, o futuro(a) professor(a) precisa, não apenas "reconhecer" este sistema educacional nos seus vários aspectos, como reconhecer-se enquanto parte dele e, portanto, produtor e produtora da sua história, corresponsável tanto pelos movimentos de permanência quanto de mutação do mesmo.

Diante dessas perspectivas, é preciso ponderar sobre o que realmente pode contribuir para a problematização de uma formação docente mais complexa, pois concordamos com Ponte (1998), que, enquanto a formação é institucional, e se dá de fora para dentro, o desenvolvimento profissional é um movimento de dentro para fora, na medida em que, o(a) futuro(a) professor(a) faz suas escolhas e toma as decisões com relação às questões que quer considerar, aos projetos que quer empreender e ao modo como os quer executar, ou seja, o professor e a professora são objetos de formação, mas são sujeitos no desenvolvimento profissional (PONTE, 1998, p.03).

Nessa linha, nos cabe auxiliá-los em seu percurso de desenvolvimento profissional por meio de uma formação que proporcione elementos que os ajude a internalizar, principalmente, durante sua preparação inicial, as disposições para pensar. Pensar na perspectiva de Deleuze (2006), na qual a característica fundamental do pensamento é que ele pode se constituir em uma potência criadora que se realiza no ato de pensar. É por isto que o autor coloca que, enquanto o pensamento se encontra relacionado ao modelo da recognição, ou seja, uma atividade de reconhecimento de um objeto comum, o ato de pensar se faz no encontro do pensamento com signos capazes de rompê-lo, violentá-lo, confrontando-o. Por isso Deleuze vai dizer que,

[...] A criação é a gênese do ato de pensar no próprio pensamento. Ora, essa gênese implica alguma coisa que violente o pensamento, que o tira de seu natural estupor, de suas possibilidades apenas abstratas (DELEUZE, 2006, p. 91).

Nessa perspectiva, a partir de uma formação que visa o desenvolvimento profissional, precisamos oportunizar experiências instigantes, provocantes, que tenham a capacidade de problematizar e deslocar os sujeitos do 
lugar-comum. Segundo Larrosa (2002), experiência é aquilo que "nos passa", nos toca, nos acontece, e ao nos passar nos forma e nos transforma.

Para oportunizar uma experiência que tivesse o potencial de deslocar o sujeito e produzir subjetivações, utilizamos paradoxalmente, um dispositivo pedagógico constituído pela linguagem cinematográfica sobre a profissão docente. Para Larrosa (2002), os dispositivos pedagógicos têm uma forma complexa, variável, contingente; às vezes contraditória, possuindo um caráter constitutivo e não meramente mediador. Assim, segundo o autor, um dispositivo pedagógico será qualquer lugar no qual se constitui ou se transforma a experiência de si.

Nesse trabalho, partimos da problematização do dispositivo pedagógico como território de produção da experiência de si, e os modos pelos quais a linguagem cinematográfica, enquanto o próprio dispositivo, se constitui como terreno de subjetivação e aprendizagem. Assim, buscamos compreender se esse dispositivo seria capaz de instigar, violentar o pensamento por meio da narrativa fílmica produzindo a "experiência de si" na interlocução com a formação inicial docente.

\section{Pensamento, cinema e formação - entrelaçamentos na experiência de si}

O cinema, a sociedade e a educação estão intimamente interligados, na medida em que esta arte constitui-se como um reflexo da temporalidade histórica, social e cultural, sendo capaz de influenciar a formação de opiniões e o comportamento das pessoas (SILVA, 2007). Segundo a autora (p. 53),

O cinema traz possibilidades infinitas, no sentido de promover a con-
templação de valores, a partir dos pontos de vista político, estético e
ético. [...]. Se foi criado, em princípio, para exposições científicas e,
depois, aproveitado para fins lucrativos por uma burguesia ascenden-
te e ávida de lucros, não significa que não possamos tomar tal inven-
ção e transformá-la em um recurso educativo de grande poder.

Nessa linha, Martin (2009), coloca que o cinema, como um artefato cultural, é também um dispositivo que expressa uma multiplicidade de sentidos da realidade, que podem ser apreendidos pela capacidade de percepção das pessoas, com base em seus sentidos e na leitura que 
realizam das proposições gestadas pelo idealizador/ produtor/diretor veiculadas por meio da obra cinematográfica, a partir de seu contexto cultural e de suas histórias de vida. Nessa linha, para Marcello (2008), ao colocarmos o foco em uma obra cinematográfica não devemos buscar, naquela narrativa, o encontro com falsas ou verdadeiras imagens, mas aceitar olhar aquilo que é exposto como algo que, embora pensado e planejado por alguém, está ali, diante de nós, como senão tivesse qualquer transcendência ou intencionalidade. Segundo a autora, existe uma tensão entre a imagem e sua representação, pois a representação propõe um domínio de exterioridade como se a imagem pudesse dar conta de apreender em si, internamente, um real que lhe é exterior.

[...] a imagem é irredutível às interpretações ou às significações, pois estas são e serão sempre inesgotáveis - não por incompetência daquele que olha, mas por resistência da própria imagem, que desdobra os ditos que se fazem sobre ela, sempre em novas possibilidades, portanto, em novos ditos, que por sua vez não darão conta, por mais que se esforcem, em abarcá-la por completo. (MARCELLO, 2008, p. 507-508)

Esta tensão entre representação e imagem corrobora com a ideia de que "[...] há disjunção entre falar e ver", em Deleuze (1991, p. 73), pois a associação entre as dimensões daquilo que se vê e daquilo que se diz está mais no âmbito das possíveis articulações e complementaridades do que da dependência ou da obviedade de seu possível encadeamento (MARCELLO, 2008). Assim, entre essas possíveis articulações e complementaridades está o sujeito que vê, e que para Martin (2009) deve desenvolver uma atitude estética, pois somente sob esta condição ele poderá perceber a imagem como uma realidade estética e, assim, o cinema torna-se uma arte e não apenas uma mera distração.

Nessa direção, em Proust e os signos (2006) Deleuze convida à adoção da arte como uma perspectiva, a partir da qual a aprendizagem é problematizada, afirmando, "a arte é o destino inconsciente do aprendiz" (p.50). Especificamente, sobre a arte cinematográfica, Deleuze (2007), vai nos dizer que o cinema da imagem-tempo, não deve ser visto como um objeto superficial para reflexão teórica, ingênua e linear, mas sim como um campo de conhecimento que atua em conjunto com a filosofia, a literatura e as artes. Assim, o cinema torna-se um exercício de pensamento que não 
carece de conceitos, mas de sensações que produzem subjetividades na medida em que causa um estado de estranhamento entre o olhar e o desenrolar da estória. Segundo o autor, a potência das imagens configura uma força que incomoda, inquieta, desequilibra, na medida que possibilita a surpresa, o choque, a indagação, e nos leva ao movimento do pensar, pois tem o potencial dos encontros nas experiências, permitindo-nos habitar outros/novos territórios ainda não sentidos, ainda não vividos.

Mas, nessa mesma obra, Imagem-tempo, Deleuze (2007) nos alerta de que é preciso resistir aos clichés habitualmente encontrados no cinema comercial, ou seja, à imagem carregada de interioridade e de verdades preestabelecidas. $\mathrm{O}$ autor nos diz que, embora vivamos, supostamente, na civilização da imagem, se nosso olhar, estimulado incessantemente por uma multiplicidade de signos, não se atém a nenhum deles, é porque vivemos, na verdade, em "uma civilização do clichê" (p. 31). A partir de Bergson, Deleuze conceitua "clichê" dizendo que, quando temos uma imagem sensório-motora da coisa, na verdade não percebemos a coisa ou sua imagem inteira, percebemos sempre menos, percebemos apenas o que estamos interessados em perceber, ou melhor, o que temos interesse em perceber, devido a nossos interesses mais imediatos de cunho social e econômico, nossas crenças, ideologias, nossas exigências psicológicas, etc. Assim, o "clichê" faz desaparecer o que há de legível, e até mesmo de visível, na imagem, uma vez que trabalha com o óbvio, com o que já está dado a ser visto, com a repetição do mesmo. Assim, Deleuze nos diz que o cinema não escapa do complô dos clichês, pelo contrário, tornou-se um de seus mais importantes veículos, principalmente por meio das produções hollywoodianas.

Como não acreditar numa poderosa organização intencional, num grande e poderoso complô, que encontrou o modo de fazer os clichês circularem de fora pra dentro e de dentro pra fora? (Deleuze, 1983, pp. 256-257)

Nessa perspectiva, Martin (2009) nos alerta para a capacidade que o cinema tem de influenciar a todos quanto lhe assistam, como um artefato cultural no qual as narrativas sociais estão presentes, carregadas de identidades formuladas por modos de ser, agir e pensar estereótipos. Corroborando com esta ideia Ellsworth (2001, p. 16) afirma que, 
“[...] um filme é composto, pois, não apenas de um sistema de imagens e do desenvolvimento de uma história, mas também de uma estrutura de endereçamento que está voltada para um público determinado e imaginado". Ao articular o mundo real e o mundo da fiç̧ão, o cinema cria imagens que se encarregam de transmitir uma ideia sobre a realidade em determinado contexto, de forma que "a representação é sempre mediatizada pelo tratamento fílmico".

Assim, somente quando conseguimos perceber essa estrutura e os estereótipos constituídos intencionalmente nessas produções cinematográficas, seremos capazes, de acordo com Ellsworth (2001), de particularmente mudar, influenciar ou até mesmo controlar e também subverter a resposta do espectador a um filme específico.

Nessa linha, Larrosa (2002, p.43) nos diz que,

Os estereótipos são os lugares comuns do discurso, o que todo mundo diz, o que todo mundo sabe. Algo é um estereótipo quando convoca mecanicamente o assentimento, quando é imediatamente compreendido, quando quase não há nem o que dizer. E grande é o poder dos estereótipos, tão evidentes e tão convincentes ao mesmo tempo.

No caso dos estereótipos e os respectivos discursos que os atravessam, percebemos que os atributos relativos à profissão docente estão pulverizados nos mais diversos suportes que nos interpelam diariamente, que são os textos jornalísticos, acadêmicos, narrativas religiosas, populares, propagandas, novelas, músicas, filmes, documentos jurídicos, materiais didáticos (CHAVES, 2016, p. 219), compondo uma rede de processos de subjetivação.

Assim, nos filmes que trazem em sua narrativa fílmica histórias de professores e de professoras, Fabris (2010), aponta que trabalham essa imagem representando-a de diversas formas, desde aqueles profissionais que são amorosos, competentes, abnegados, heróis, até aqueles maquiavélicos, míseros, marcados pelos mais diferentes estereótipos presentes nas mais variadas obras cinematográficas.

Torna-se necessário, então, problematizar e desnaturalizar os endereçamentos e seus respectivos discursos sobre as estórias/histórias que estão contidas nas obras cinematográficas sobre as representações docentes. Para tanto, faz-se necessário apropriar-se do filme como linguagem cinema- 
tográfica capaz de constituir experiências singulares, que de acordo com Alves (2010, p.12), implica em,

[...] elaborar metodologias pedagógicas capazes de ir além da mera exibição do filme e inclusive, da mera discussão entretida da narrativa fílmica, [...] ir além da tela no sentido de criar por meio de uma nova prática [...], um novo espaço de produção de conhecimento crítico apropriado pelos sujeitos-receptores, que são sujeitos-produtores de uma consciência crítica do mundo.

Ao reconhecer essa necessidade, precisamos oportunizar experiências durante o percurso de formação de professoras e professores, que possam proporcionar o parar para pensar. Para Larrosa (2002), a palavra "experiência", tanto nas línguas germânicas como nas latinas, contém inseparavelmente a dimensão de travessia e perigo, como uma relação com algo que se experimenta, que se prova. Segundo o autor, a experiência é de ordem epistemológica, ética e estética, na medida que o saber de experiência se dá na relação e mediação entre o conhecimento e a vida humana. Para Larrosa (2002), o saber da experiência é um saber que não está, como o conhecimento científico, fora de nós, mas é um saber particular, subjetivo, relativo, contingente, pessoal. Se a experiência não é o que acontece, mas o que nos acontece, duas pessoas, ainda que enfrentem o mesmo acontecimento, não fazem a mesma experiência (p. 27). Ou seja, o autor nos provoca a pensar a experiência do ponto de vista da formação e da transformação da subjetividade, em que o sujeito da experiência é um espaço onde têm lugar os acontecimentos (LARROSA, 2002, p. 24), estando somente ele aberto à sua própria transformação. Nesse âmbito, o sujeito da experiência é visto como aquele que se expõe atravessando um espaço indeterminado $e$ perigoso, pondo-se nele à prova e buscando nele sua oportunidade, sua ocasião (p. 25). Para isso, é necessário, segundo o autor, que esse sujeito seja capaz de um gesto de interrupção, de parada para olhar, escutar, sentir, pensar.

Por isso é incapaz de experiência aquele que se põe, ou se opõe, ou se impõe, ou se propõe, mas não se "ex-põe". É incapaz de experiência aquele a quem nada lhe passa, a quem nada lhe acontece, a quem nada lhe sucede, a quem nada o toca, nada lhe chega, nada o afeta, a quem nada o ameaça, a quem nada ocorre (LAROSSA, 2002, p. 25) 
Por isso, seja como território de passagem, seja como lugar de chegada ou como espaço do acontecer, o sujeito da experiência é aquele que, segundo Larrosa $(2002$, p.24),

[...] é alcançado, tombado, derrubado. Não um sujeito que permanece sempre em pé, ereto, erguido e seguro de si mesmo; não um sujeito que alcança aquilo que se propõe ou que se apodera daquilo que quer; não um sujeito definido por seus sucessos ou por seus poderes, mas um sujeito que perde seus poderes precisamente porque aquilo de que faz experiência dele se apodera.

Dentro dessa perspectiva, Larrosa (1994) traz a genealogia e a pragmática da "Experiência de $\mathrm{Si}$ ", por meio de uma proposição teórica, como um jogo, com a obra de Michel Focault, na qual faz aproximações entre "subjetividade" e "experiência de si mesmo". Segundo Larrosa (1994), a ontologia do sujeito é o mesmo que a experiência de si, pois há um sujeito porque é possível traçar a genealogia das formas de produção dessa experiência. Dessa forma, o sujeito, sua história e sua constituição como objeto para si mesmo, seriam inseparáveis das tecnologias do eu (LARROSA, 1994, p.53). Esse autor, traz Foucault (1990), para definir as tecnologias do eu como aquelas nas quais um indivíduo estabelece uma relação consigo mesmo. Nesse sentido, Larrosa (1994, p. 54), para mostrar a construção e a mediação pedagógica da experiência de si, nos traz a correlação entre esta e um dispositivo pedagógico.

A experiência de si seria, então, a correlação, em um corte espaçotemporal concreto, entre domínios de saber, tipos de normatividade e formas de subjetivação. E é uma correlação desse tipo que se pode encontrar, também, em um corte espaço-temporal particular, na estrutura e no funcionamento de um dispositivo pedagógico.

Segundo o autor, um dispositivo pedagógico será qualquer lugar no qual se aprendem ou se modificam as relações que o sujeito estabelece consigo mesmo, ou seja, qualquer lugar no qual se constitui ou se transforma a experiência de si. Larrosa faz aproximações teóricas com a obra de Focault, no que diz respeito à elaboração dos dispositivos pedagógicos, nos quais se constrói a experiência de si. Para tal, Larrosa (1994), introduz um modelo teórico no qual, por meio de um dispositivo pedagógico, a experiência de si pode ser analisada como resultado do entrecruzamento de tec- 
nologias óticas de autorreflexão, formas discursivas (basicamente narrativas) de autoexpressão, mecanismos jurídicos de autoavaliação, e ações práticas de autocontrole e autotransformação. Dessa forma, o sujeito, na medida em que mantém uma relação reflexiva consigo mesmo, não é senão o resultado dos mecanismos nos quais se observa, se decifra, se interpreta, se julga, se narra ou se domina, ou seja, nos quais essa relação se produz e se medeia.

Neste caminho, levando em conta o cinema e sua linguagem como uma arte capaz de nos sensibilizar, e como um signo catalisador na possibilidade de aprendizagens, utilizamos textos filosóficos e obras cinematográficas sobre professores e professoras como um dispositivo pedagógico, cujos mecanismos são voltados para provocação do pensar dos sujeitos na experiência de si

\section{Ensaio metodológico}

O percurso metodológico desse estudo levou em conta que a linguagem cinematográfica, como dispositivo pedagógico, pode promover uma educação problematizadora. Pois, pensamos que esse dispositivo carrega em si o potencial de um exercício estético/filosófico, que pode provocar um pensar-viver-construir mundos, e nos auxiliar a (re)pensar nossa posição nele.

Nesse âmbito, buscamos oportunizar a experiência de si como dispositivo pedagógico em dois filmes: A voz do coração (Les Choristes, França, 2004) e Sociedade dos poetas mortos (Dead Poets Society, USA, 1989). Para análise utilizamos as micronarrativas produzidas pelos licenciandos e licenciandas durante a realização da atividade proposta. Por narrativa, entendemos ser o local da experiência no discurso. O narrador é aquele que ainda é capaz de transmitir a experiência, pois aquilo que conta deriva tanto de suas experiências quanto do que lhe foi relatado (Fonseca et al., 2015, p. 229). Assim, nossa intenção foi de oportunizar a produção de micronarrativas que falassem sobre como a linguagem cinematográfica nos afetou enquanto "experiência de si". A partir disso, estabelecemos conexões com os estudos de Larrosa e a experiência de si para dialogar com as micronarrativas produzidas por meio do dispositivo pedagógico proposto. Nessa linha, utilizamos as dimensões colocadas pelo autor como categorias, para fazer 
os entrelaçamentos entre as micronarrativas dos sujeitos e a narrativa fílmica dentro da experiência vivenciada.

Temos, então, até aqui, várias dimensões da experiência.

-Exterioridade, alteridade e alienação têm a ver com o acontecimento, com o que é da experiência, com o isso do "isso que me passa".

-Reflexividade, subjetividade e transformação têm a ver com o sujeito da experiência, com o quem da experiência, com o me de "isso que me passa".

-Passagem e paixão têm a ver com o movimento mesmo da experiência, com o passar do "isso que me passa" (LARROSA, 2011, p.06)

O contexto do estudo foi a disciplina Metodologia de Ensino, componente curricular do curso de Ciências Biológicas de uma Universidade Federal, durante a qual foi proposta uma atividade que aliava textos sobre correntes filosóficas a obras cinematográficas.

Os dados para análise foram obtidos por meio das micronarrativas de dois sujeitos (Jonas e Lorrane), que foram escolhidos como representantes dos 21 alunos e alunas que fizeram a atividade.

\section{Análise e Discussão dos Resultados}

A linguagem fílmica está repleta de possibilidades narrativas, que ganham força tendo como suporte nossa memória cultural e social, fazendo desses elementos não apenas parte da imaginação, mas conteúdo imprescindível para produção de sentidos. A proposta da atividade, anteriormente mencionada, levava em conta que, no encontro do licenciando com uma obra cinematográfica está a experiência de si, irrepetível e única. Nas singularidades dessa experiência nos perguntamos o que ficará na memória de cada um(a) e será exposto, narrado.

Para Jonas,

(...) o trabalho foi de grande valia para minha formação tanto profissional, como pessoal, pois através desse trabalho foi possível ver de uma forma mais humana, o comportamento das pessoas e a evolução do pensamento, ressaltando a importância de analisar o ambiente social em que cada um vive, as pessoas com quem se relacionam e a realidade local. 
O estudo sobre os métodos pedagógicos e sua evolução, ressaltando o processo de mudança explicita o dinamismo nos processos educativos, em busca de uma melhor compreensão e adaptação ao aluno. Isso me fez refletir sobre as antigas falhas, que se repetem ainda hoje, devido à ausência do estudo das antigas políticas pedagógicas. (Jonas)

Partindo do princípio da reflexividade, percebemos que, para Jonas, a experiência se deu como um movimento de ida e volta. Ida, porque a experiência supõe um movimento de exteriorização, de saída de si mesmo indo ao encontro do acontecimento, e um movimento de volta, na medida em que a experiência supõe que o acontecimento afeta a mim, que produz efeitos em mim, no que eu sou, no que eu penso, no que eu sinto, no que eu sei, no que eu quero, etc. (LARROSA, 2011, p. 47). Entretanto, apesar de movimentos de reflexividade, Jonas parece estar observando, julgando, interpretando e narrando "o outro", como apenas um reconhecimento da representação fílmica, o que não deixa de ser um processo de subjetivação. Fonseca (1995), se referenciando na obra de Foucault, indica que os processos de subjetivação podem ser compreendidos a partir da análise da maneira pela qual cada indivíduo se relaciona com o regime de verdades próprio a cada período, isto é, a forma como o conjunto de regras que define cada sociedade é experienciado em cada trajetória de vida. Nesse caso, observamos que Jonas demonstra estar ciente dos discursos que o atravessam (Isso me fez refletir sobre as antigas falhas, que se repetem ainda hoje, devido à ausência do estudo das antigas políticas pedagógicas), indicando um reconhecimento dos modelos pedagógicos apresentados na obra cinematográfica.

Na premissa da transformação proposta por Larrosa (2011, p.07) como "isso que me passa", esse sujeito ex/posto seria aberto à sua própria transformação, numa relação constitutiva entre a ideia de experiência e a ideia de formação, na qual o sujeito da experiência não seja o sujeito do saber, ou o sujeito do poder, ou o sujeito do querer, senão o sujeito da formação e da transformação. Assim, em sua narrativa, Jonas, ao fazer uma alusão direta à contribuição da atividade proposta para sua formação oferece indícios de uma transformação na perspectiva colocada por Larrosa, nesse momento particular e histórico de sua experiência. Por outro lado, ao reforçar discursos externos e reconhecer modelos como certos ou errados, Jonas vai ao encontro das representações docentes sem tensioná-las com outras 
possibilidades da imagem, o que pode indicar apenas o pensamento sobre e não o pensar de fato.

Lorrane, por sua vez, traz em sua narrativa movimentos de reflexividade na experiência de si permeados por outros discursos que identifica no dispositivo pedagógico, tais como a desvalorização dos cursos de Arte e Literatura que aparece no filme.

Isso fica bem visível numa cena em que o aluno não consegue convencer o pai, que exige que ele deixe suas atividades como redator do anuário escolar, e até quando o pai aborda-o depois de descobrir que está participando de uma peça teatral.

Reconhece também, questões relacionadas a gênero e poder ao expressar,

O que pode ser notado muito também é que o homem com a sua razão usa imagem feminina para tirar aproveito. Prova disso é quando o pai de Neil fala sobre a decepção e tristeza que ele irá causar à sua mãe se insistir nas ideias de abandonar o ingresso na Medicina pra cursar Arte Dramática. O que fica marcado é que o sexo feminino possui um poder menor que o oposto, ou seja, a mulher ainda não tem poder para opinar nas decisões do homem.

Ao trazer seu entrelaçamento com a linguagem desses discursos que se constituem na subjetividade do masculino e do feminino, nas relações sociais e de poder, e na construção social do gênero, podemos perceber que, para Lorrane, o dispositivo pedagógico produz modos de subjetivação distintos. Pois, os discursos apreendidos, pensados e narrados com criticidade pela aluna são aqueles que a narrativa fílmica dá a entrever, mas não necessariamente a ver, portanto pode-se notar que ela é um sujeito ex/posto, sensível, vulnerável "ao que me passa". Embora, a produção desses discursos tenha se dado em um momento histórico/social já passado, podemos ver a potência da narrativa fílmica no que Deleuze (2007) denomina como imagem-tempo, na qual o tempo consiste em uma cisão que, faz passar todo o presente e também conserva todo o passado. Ao explicarem a imagem-tempo em Deleuze, Rodrigues e colaboradores (2010, p. 7-8) dizem que, 
É esta cisão que se vê no cristal. A imagem-cristal não é o tempo, mas vemos o tempo no cristal. Porém, o cristal, onde vemos jorrar o tempo não-cronológico, é constituído por duas imagens distintas - a atual do presente que passa e a virtual do passado que se conserva - que apresentam-se indiscerníveis justamente por serem distintas, já que não se sabe qual é uma e qual é outra, como uma imagem mútua onde coexistem a subjetividade (que nunca está em nós mas no tempo) do virtual e a objetividade do atual.

Portanto, podemos perceber que a licencianda vê e sente os discursos no presente/passado da experiência, nesse sentido, a experiência passa a ter outras configurações que talvez sejam distintas das vivências do sujeito, mas que ao mesmo tempo se fazem presentes por meio do dispositivo pedagógico na experiência de si. Assim, o sujeito da experiência se dá a ser alcançado, tombado, derrubado (LARROSA, 2001, p. 25).

Lorrane também, quando analisa a representação do professor no filme, expressa que,

(...) o professor tem como proposta de ensino com base no próprio processo de viver. Ele diz que a educação deveria se confundir com nossa vida. As suas propostas de ensino fogem do paradigma estabelecido pelo internato; uma vez que o professor utiliza de outros espaços, considerados não convencionais pra propor atividades diferentes, fazendo com que a convivência entre os alunos seja agradável. O filme mostra cenas como as que o professor encoraja seus alunos a subirem na mesa, falarem alto, e até arrancar as páginas de um livro (...)

Demonstra assim, indícios do que Larrosa $(2011$, p. 08) chama de "princípio de paixão". O autor vem nos dizer que, se a experiência é "isso que me passa", então o sujeito da experiência é como um território de passagem, como uma superfície de sensibilidade em que algo, ao passar por mim ou em mim, deixa um vestígio, uma marca, um rastro, uma ferida.

Daí que o sujeito da experiência não seja, em princípio, um sujeito ativo, um agente de sua própria experiência, mas um sujeito paciente, passional. Ou, dito de outra maneira, a experiência não se faz, mas se padece. A este segundo sentido do passar de "isso que me passa" poderíamos chamar de "princípio de paixão". 
Nesse movimento, observamos em sua micronarrativa que a licencianda foi capaz de deixar que algo lhe passasse, que a experiência lhe alcançasse, posto que expressa, (...) que sejamos críticos, criativos e pensadores. $O$ aluno deve questionar, dar opiniões e pesquisar, para que seu conhecimento não fique apenas no que foi dito. Demonstra assim indícios do princípio de transformação, aproximando da relação constitutiva entre a ideia de experiência e a ideia de formação, que, de acordo com Larrosa (2011), será a formação ou a transformação do sujeito da experiência.

Vimos assim, que o mesmo dispositivo produz experiências de si únicas e singulares, reafirmando o que Larrosa (2002, p.27) coloca como duas pessoas, ainda que enfrentem o mesmo acontecimento, não fazem a mesma experiência. O que reforça a visão de Napolitano (2009, p. 15), de que a experiência cultural e estética do cinema vai além de qualquer metodologia de análise dos filmes e que o ato de assistir a um filme é uma experiência formativa em si e por si.

\section{Considerações finais}

Pensamos que a linguagem cinematográfica é muito mais que simplesmente imagens em movimento, pois incorpora múltiplas dimensões técnicas e estéticas que cria um complexo sistema de significações. Significações presentes nas histórias que nos arrebatam, nos interpelam, porque envolvem o prazer, o sonho, a imaginação que transcendem as fronteiras do consciente, cristalizando o tempo e embaralhando os limites entre realidade e ficção.

Para Deleuze (2007), a imagem cinematográfica guarda o poder de trazer a autenticidade da duração, a densidade dos instantes, a contemporaneidade do passado, passando a ser muito mais do que uma representação do mundo, mas torna-se uma busca de mundos que nos mostram a possibilidade de um vir a ser, de nos projetarmos num ainda por vir. $\mathrm{Na}$ imagem estamos num tempo que não "passa", mas conserva-se como virtualidade disponível em todos os seus pontos para atualizações diversas e segundo as mais insólitas conexões.

Assim, nesse trabalho buscamos a problematização das representações docentes em obras cinematográficas como um dispositivo pedagógico que pretende provocar o pensar na experiência de si. Larrosa vai nos dizer que a experiência não depende do objeto nem do sujeito, mas é o que 
ocorre "entre" que constitui e transforma a ambos. No "entre", ocorre a relação e a mediação que tem o poder de fabricar o que relaciona e o que medeia, é o que os dispositivos pedagógicos produzem e capturam.

O que capturamos nas micronarrativas dos alunos e alunas nos indicam que a linguagem fílmica no dispositivo pedagógico revela seu potencial imagem-tempo na experiência de si. Assim, percebemos que, a linguagem cinematográfica como um dispositivo pedagógico, pode contribuir para a problematização de modos instituídos de viver, promovendo contribuições estético/político/pedagógicas de subjetividade, e nos auxiliando na problematização do modo como têm sido feitas as leituras das imagens fílmicas relativas aos professores e professoras. Também, pensamos aqui em outros modos de formação em interlocução com a linguagem fílmica como dispositivo pedagógico, porém com cuidado para não o reduzir a apenas mais um recurso didático-metodológico para a aprendizagem da docência, mas, principalmente, como um momento de abertura para novas práticas formativas e outros modos de subjetivação. Sabemos que há um vasto território a ser explorado dentro desse tema, mas esperamos que esse trabalho possa contribuir para outros estudos e outras conversas.

\section{Referências}

ALARCÃO, Isabel. Reflexão crítica sobre o pensamento de D. Schön e os programas de formação de professores, in I. Alarcão (Org.), Formação Reflexiva de Professores. Estratégias de Supervisão. Porto: Porto Editora, pp. 1039, 1996.

ALVES, Giovanni. O cinema como experiência crítica: tarefas políticas do novo cineclubismo no século XXI. In: ALVES, Giovanni e MACEDO, Felipe (Orgs.). Cineclube, cinema \& educação. Londrina: Práxis; Bauru: Canal 6, 2010.

CARVALHO, Janete Magalhães. Currículos entre imagens, sensações e afecções. In: Seminário Internacional as Redes Educativas e as Tecnologias, 7., 2013, Rio de Janeiro. Anais... Rio de Janeiro: Proped/Uerj, 2013. 
CHAVES, Sílvia. N.. Um currículo para despertar adultos e adormecer crianças. In: CHAVES, Sílvia N.; SILVA, Carlos Aldemir F.; BRITO, Maria R. (Org.). Cultura e Subjetividade: Perspectivas em Debate. 1ed.São Paulo: Editora Livraria da Física, 2016, v. 1, p. 215-226.

DELEUZE, Gilles. Cinema I: A imagem-movimento. São Paulo, SP: Brasiliense, 1983.

DELEUZE, Gilles. Proust e os signos. Rio de Janeiro: Forense Universitária, 2006.

DELEUZE, Gilles. Foucault. São Paulo: Brasiliense, 1991.

DELEUZE, Gilles. 1985. L'image-temps. Paris, Minuit. Trad. bras. A ImagemTempo. São Paulo, Brasiliense, 2007.

ELLSWORTH, Elizabeth. Modos de endereçamento: uma coisa de cinema; uma coisa de educação também. In: SILVA, Tomaz Tadeu da. Nunca fomos humanos: nos rastros do sujeito. Belo Horizonte: Autêntica, 2001.

FABRIS. Eli Terezinha Henn. A pedagogia do herói nos filmes hollywoodianos. In: Currículo sem Fronteiras, v.10, n.1, p.232-245, Jan/Jun 2010.

FONSECA, Márcio Alves. Michel Foucault e a constituição do sujeito. São Paulo: EDUC, 1995.

FONSECA, Tânia Maria Galli; Costa, Luís. Arthur; Cardoso Filho, Carlos Antônio; e Garavelo, Leonardo Martins Costa. Narrativas das infâmias: um pouco de possível para a subjetivação contemporânea. Athenea Digital. Revista de Pensamiento e Investigación Social, 15(1), 225- 247, 2015.

FOUCAULT, Michel. Tecnologias del yo. In: Tecnologías del yo y otros textos afines. Barcelona, Paidós, 1990

LARROSA, Jorge. Tecnologias do Eu e Educação. In: SILVA, T. T. O sujeito da educação: estudos foucaultianos. Petrópolis: Vozes: 1994.

LARROSA, Jorge. Notas sobre a experiência e o saber de experiência. 2002. 
LARROSA. Jorge. Experiência e alteridade em educação. Revista Reflexão e Ação, Santa Cruz do Sul, v. 19, n2, p.04-27, jul./dez. 2011.

MARCELLO, Fabiana de Amorim. Cinema e educação: da criança que nos convoca à imagem que nos afronta. Rev. Bras. Educ., Rio de Janeiro, v. 13, n. 38, p. 343-356, agosto. 2008.

MARTIN, Marcel. A linguagem cinematográfica. 2 reimp. Da 1. ed. de 1990. São Paulo: Brasiliense, 2009.

NAPOLITANO, Marcos. Como usar o cinema na sala de aula. São Paulo: Ed. Contexto, 2003.

PONTE, João Pedro. Didácticas específicas e construção do conhecimento profissional. In: Investigar e formar em educação. IV congresso da SPCE. Porto, Actas..., Porto, Sociedade Portuguesa de Ciências da Educação, 1998.

RODRIGUES, Sara Martin; Farias, Edson Silva de; Fonseca-Silva, Maria da Conceição. O cinema por Deleuze: imagem, tempo e memória. In: VI ENECULT - Encontro de Estudos Multidisciplinares em Cultura. Salvador, Anais..., Salvador, 2010.

SILVA, Roseli Pereira. Cinema e educação. São Paulo: Cortez, 2007.

VILLANI, Alberto; FRANZONI, Marisa; VALADARES, Juarez Melgaço. Desenvolvimento de um grupo de licenciandos numa disciplina de prática de ensino de Física e Biologia. Investigações em Ensino de Ciências, v. 13, p. 143168, 2008. 